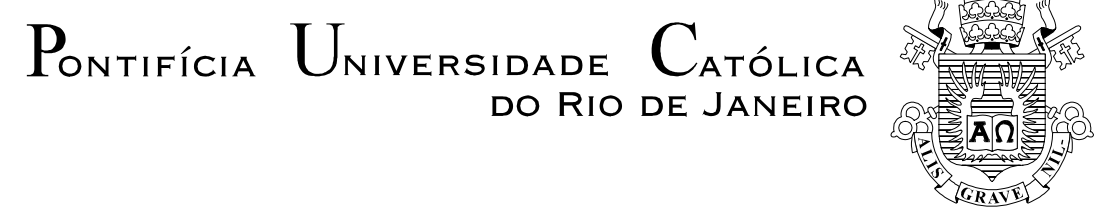

Adriana Vidal de Oliveira

\title{
A EXPRESSÃO CONSTITUINTE DO FEMINISMO: Por uma retomada do processo liberatório da mulher
}

\author{
Dissertação de Mestrado
}

Dissertação apresentada como requisito parcial para obtenção do grau de Mestre pelo Programa de Pósgraduação em Direito do Departamento de Direito da PUC-Rio.

Orientador: Prof. Adriano Pilatti

Rio de Janeiro

julho de 2007 


\title{
A EXPRESSÃO CONSTITUINTE DO FEMINISMO: Por uma retomada do processo liberatório da mulher
}

\begin{abstract}
Dissertação apresentada ao Programa de Pósgraduação em Direito do Departamento de Direito da PUC-Rio como parte dos requisitos parciais para a obtenção do título de Mestre em Direito.
\end{abstract}

\author{
Prof. Adriano Pilatti \\ Orientador \\ Departamento de Direito - PUC-Rio
}

Prof. Francisco de Guimaraens

Departamento de Direito - PUC-Rio

Prof $^{a}$. Leonora Figueiredo Corsini UFRJ - LABTEC

Prof. ${ }^{\circ}$ João Pontes Nogueira Vice-Decano de Pós-Graduação do Centro de Ciências Sociais - PUC-Rio

Rio de Janeiro, 12 de julho de 2007. 
Todos os direitos reservados. É proibida a reprodução total ou parcial do trabalho sem a autorização do autor, do orientador e da universidade.

\section{Adriana Vidal de Oliveira}

Graduada em Direito pela PUC-RIO em 2003 e pós-graduada em Direito pela mesma universidade em 2007. Áreas de interesse são Feminismo, Filosofia do Direito, Teoria do Direito e Teoria do Estado.

Ficha Catalográfica

Oliveira, Adriana Vidal de

A Expressão Constituinte do Feminismo: por uma retomada do processo liberatório da mulher / Adriana Vidal de Oliveira; orientador: Adriano Pilatti - Rio de Janeiro: PUC, Departamento de Direito, 2007.

179f. ; $30 \mathrm{~cm}$

Dissertação (mestrado) - Pontifícia Universidade Católica do Rio de Janeiro, Departamento de Direito.

Inclui referências bibliográficas.

1. Direito - Teses. 2.Judith Butler. 3.Feminismo. 4.Atos Performativos. I. Pilatti, Adriano. II. Pontifícia Universidade Católica do Rio de Janeiro. Departamento de Direito. IV. Título. 


\section{Agradecimentos}

É muito comum a reclamação entre os mestrandos de que o trabalho de elaboração da dissertação é bastante solitário. Sem dúvida, o momento da escrita ficou restrito, na maior parte do tempo, a essa reclusão. Porém, seria uma extrema injustiça atribuir a realização do trabalho somente a esse momento, quando na verdade, essa foi a menor parte. Além disso, após esse ingresso nos estudos da multidão, descobri, nas palvras de Deleuze e Guattari, que "cada um de nós já é vários" e que há um movimento contínuo entre as singularidades e a multidão. Definitivamente, esse não é um trabalho solitário. Fica aqui registrado o agradecimento à multidão que o produziu.

Ao meu orientador Adriano Pilatti e ao professor Francisco de Guimaraens, que me apresentaram ao autor Antonio Negri, me orientaram no ingresso em sua teoria e foram os grandes responsáveis pelo meu interesse nesse caminho trilhado pela tradição de pensamento da qual o autor faz parte. O professor Florian Hoffman também teve um papel importante nessa trajetória, com as críticas e observações feitas em relação ao projeto de dissertação. Aos secretários Anderson e Carmen, pelo carinho e pela atenção com que sempre atendem aos alunos da pós-graduação da PUC

Aos meus pais, sempre muito especiais, que foram importantes nesse momento, pois me apoiaram e deram a melhor estrutura que podiam desde que decidi participar da seleção do mestrado até o momento da impressão da dissertação. Meu irmão também foi fundamental, pois sempre foi um exemplo de tranqüilidade no meio da turbulência.

Já que o tema é multidão e heterogeneidade, os queridos amigos que me acompanharam ao longo desse caminho merecem ser lembrados nesse momento, especialmente a minha turma de mestrado, que apesar das divergências de experiências e de convicções teóricas, soube constituir um comum sem desprezar as singularidades. Um especial agradecimento à grande amiga Tatiana Figueiredo, que me deu apoio nos estudos para a prova do mestrado e às amigas Karen, Ligia, Livia, Paula e Samantha, não só interlocutoras da melhor qualidade quando a questão é acadêmica, mas também doutoras quando o tema é diversão.

Por fim, um agradecimento especial ao meu grande amor Rodrigo de Souza Costa, que entrou na minha vida há tão pouco tempo, porém, produziu transformações radicais e abraçou como uma causa própria a dissertação. Além disso, seu apoio e carinho incondicionais foram fundamentais para a produção desse trabalho. 


\section{Resumo}

Oliveira, Adriana Vidal de; Pilatti, Adriano (Orientador). A expressão constituinte do feminismo: por uma retomada do processo liberatório da mulher. 2007. 179p. Dissertação de Mestrado - Departamento de Direito, Pontifícia Universidade Católica do Rio de Janeiro.

Existe uma grande variedade de teorias feministas. Cada uma fundamenta a conquista de direitos das mulheres de forma bem distinta. O surgimento das vertentes do feminismo ocorre segundo as necessidades e os interesses em disputa da época em que elas são cunhadas. Por esse motivo, muitas podem, a princípio, ter uma aparência inovadora, de ruptura com uma determinada estrutura de poder imposta sobre o corpo da mulher. Porém, quando analisadas com o auxílio da perspectiva de poder constituinte trabalhado pelo autor Antonio Negri, a aparência de liberação não se sustenta, demonstrando que, na verdade, pode ser resultado de um esforço em sentido contrário ao processo revolucionário, um esforço próprio do poder constituído para frear a liberação da mulher. Nesse sentido, a autora Judith Butler tece importantes críticas a categorias utilizadas de forma bastante freqüente não somente pelo feminismo, como também por outros movimentos de minorias; estratégias de luta que, em vez de auxiliar na expansão do feminismo, acabam fazendo com que o movimento feminista e suas teóricas ou teóricos usem o mesmo aparato do poder para criar condições desiguais para as mulheres. Um desses recursos é o apelo à identidade, que exclui diversas categorias do movimento e é fundamental para a elaboração do conceito de Outro. As críticas a essa estratégia tradicional, bem como a teoria fundada pela autora ajudam a pensar em uma nova forma de se retomar o processo liberatório das mulheres.

\section{Palavras-chave}

Judith Butler, Feminismo, Processo Revolucionário, Atos Performativos, Mulher, Liberação, Multidão, Poder Constituinte, Antonio Negri 


\section{Abstract}

Oliveira, Adriana Vidal de; Pilatti, Adriano (Advisor). The Constituent Expression of Feminism: for the retaking of the woman liberation. Rio de Janeiro, 2007. 179p. Dissertação de Mestrado - Departamento de Direito, Pontifícia Universidade Católica do Rio de Janeiro.

There is a great variety of feminist theories. Each one of them explains the achievement of women rights in a different way. Feminism theories emerged according to the necessities and conflict of interests of the period in which they were created. For this reason, much of them may appear in the first moment to be innovative, to be going against certain power structure imposed upon woman's body. Nevertheless, when those theories are analyzed through the lens of the constituent power perspective used by Antonio Negri, the liberation perspective does not hold itself. In fact, they seem to be the result of an opposite effort towards the revolutionary process, an effort of the constituted power to break the liberation of women. In this sense, Judith Butler makes important criticisms to the frequently-used categories by the feminism movement and other minority movements. According to her, the struggle strategies used by minority movements lead the feminist movement to utilize the same apparatus of power that create unequal conditions for women, instead of supporting feminism expansion. One of the resources used is the appeal to identity, which excludes several categories of the movement and is essential to the elaboration of the Other concept. The criticisms to this traditional strategy as well as the theory founded by Butler help to enlighten a new way to retake the liberation process of women.

\section{Keywords}

Judith Butler, Feminism, Revolutionary Process, Performative Acts, Woman, Liberation, Multitude, Constituent Power, Antonio Negri 


\section{Sumário}

Introdução

1. Pressupostos teóricos para a reflexão sobre o tema

1.1 Multidão e Imanência: a multiplicidade de singularidades e a

viabilização desse processo pela ausência de modelo

$1.2 \mathrm{O}$ poder constituinte na concepção da tradição herdada por

Antonio Negri e Michael Hardt

2. Os processos revolucionários das mulheres: experiências preparatórias da primeira e da segunda onda do feminismo no ocidente

2.1Os primeiros conventos como uma possibilidade de fuga do casamento: a mobilidade da mulher no início do Cristianismo

2.2Da Renascença às revoluções americana e francesa: os esforços da modernidade para impedir os processos liberatórios das mulheres

2.3As incoerências do contratualismo como suporte para a teoria feminista

$2.4 \mathrm{O}$ surgimento da primeira onda de feminismo

$2.5 \mathrm{O}$ impacto da segunda onda do feminismo na década de 1960

3. Pelo retorno ao processo liberatório da mulher: a crítica de Judih Butler às estratégias de luta feminista e sua proposta para retomada do poder constituinte

3.1 Os fundamentos da Teoria Queer: uma perspectiva inovadora sobre o feminismo

3.2 A apropriação dos atos performativos pela multidão: uma possibilidade subversiva

Conclusão 
Nada é impossível de mudar Desconfiai do mais trivial, na aparência singelo. E examinai, sobretudo, o que parece habitual. Suplicamos expressamente: não aceiteis o que é de hábito como coisa natural, pois em tempo de desordem sangrenta, de confusão organizada, de arbitrariedade consciente, de humanidade desumanizada, nada deve parecer natural nada deve parecer imutável (Bertold Brecht) 